\title{
Complexo econômico-industrial da saúde: desafios e impasses
}

\author{
The health economic and industrial complex: challenges and \\ impasses
}

\author{
Complejo económico-industrial de la salud: desafíos y puntos \\ muertos
}

BRASIL SAÚDE AMANHÃ: COMPLEXO ECONÔMICO-INDUSTRIAL DA SAÚDE. Gadelha CAG, Gadelha P, Noronha JC, Pereira TR, organizadores. Rio de Janeiro: Editora Fiocruz; 2017. 227 p. ISBN: 97885-7541-490-3

doi: 10.1590/0102-311X00126418

O livro Brasil Saúde Amanhã: Complexo Econômico-Industrial da Saúde, publicado pela Editora Fiocruz, vem suprir uma importante lacuna na produção bibliográfica sobre o tema no país. Organizado por Carlos Augusto Grabois Gadelha, Paulo Gadelha, José Carvalho de Noronha e Telma Ruth Pererira, apresenta um painel sobre o projeto coordenado pelo Grupo de Pesquisa Inovação em Saúde da Fiocruz, nas últimas décadas.

O debate sobre saúde e capitalismo norteou a construção teórica do ideário da Reforma Sanitária no Brasil. Discutir as formas de reprodução do capital na saúde e seu processo de acumulação era corriqueiro nas décadas de 1970 e 1980. Concomitantemente à institucionalização e consolidação do Sistema Único de Saúde (SUS) nas décadas subsequentes, registra-se o declínio desse debate no plano teórico da produção científica da saúde no país.

O livro discute as áreas incluídas no conceito de complexo econômico-industrial da saúde (CEIS). Esse seria demarcado por três subsis- temas produtivos: indústrias de base química e biotecnológica; mecânica, eletrônica e de materiais; e serviços de saúde. A produção desses segmentos confluiria para a prestação de serviços em saúde 1 .

A formulação inicial sobre esse campo remonta o marco teórico do "complexo médico-industrial da saúde”, formatado na década de 1980. Estudava as relações entre a produção e a circulação de medicamentos, a organização da prática médica, as formas de intervenção estatal no setor e as práticas concretas de consumo individual, e a determinação desse complexo nas práticas de consumo de bens e serviços de saúde 2 .

A análise crítica sobre os subsistemas do CEIS é o cerne da publicação. Surge aí uma grande potência do livro, ao confirmar nas premissas listadas que a sustentação estrutural do SUS deve estar associada à consolidação de uma base produtiva e de inovação em saúde.

Outro apontamento do livro é a análise da reprodução das forças capitalistas na saúde, direcionando o processo de acumulação de inovação e capital. Valendo-se de uma análise dialética, defende-se a necessidade de intervenção do Estado e da base social de sustentação para orientar e regular o movimento do capital e a interação com este. Isso é fundamental para que o desenvolvimento das forças produtivas não gere relações sociais excludentes e desvinculadas das necessidades sociais.

O livro registra que o aumento do acesso a serviços públicos de saúde no Brasil, identificado 
entre 2003 e 2013, foi concomitante ao da quadruplicação do déficit comercial, causada pela dependência tecnológica. Oportuna reflexão apontada na publicação é o fato de a saúde ser um dos principais blocos de inovação e desenvolvimento no panorama internacional do século XXI. A inserção do Brasil na geopolítica internacional é crucial para a consolidação de avanços em áreas estratégicas como as de biotecnologia, química avançada, nanotecnologia, novos materiais, microeletrônica e tecnologia da informação.

Deve-se elogiar o recurso adotado pelos organizadores em dividir o temário por capítulos referentes aos subsistemas do CEIS. O primeiro capítulo aborda a geração e as trajetórias de inovação nos serviços de saúde. Baseando-se no princípio de que a inovação deva ser vista na perspectiva da ampliação da efetividade dos serviços de saúde, as autoras reafirmam a inconsistência entre o gasto público em saúde, sua distribuição e a conformação de um sistema universal, recomendando a necessidade simultânea de incremento do financiamento público para os serviços e o fortalecimento da base produtiva nacional.

A ênfase das autoras é na reflexão sobre a inovação nos serviços hospitalares, apresentando recomendações sobre a agenda de linhas de pesquisas para a área de inovações em serviços de saúde. A limitação do texto diz respeito à concentração da análise no setor hospitalar, privando o leitor de reflexões de investimentos em outras organizações prestadoras de serviços em saúde, como os ambulatórios e serviços de diagnóstico e tratamento, inseridos no conceito de CEIS 3.

No segundo capítulo, o autor aborda a indústria de base química no Brasil e suas potencialidades, desafios e nichos estratégicos. Ao propor que o desenvolvimento do setor farmacêutico nacional fosse capaz de articular o esforço de inovação e produção com a resolução de problemas sanitários locais, o autor aponta para um declínio de produtividade na pesquisa e desenvolvimento na indústria farmacêutica global, nos últimos anos.

Outra tendência detectada pelo autor é a do aumento da participação dos mercados emergentes nas vendas de medicamentos, com o Brasil apresentando um incremento expressivo a partir de 2012. Entretanto, inexiste no artigo análise mais aprofundada sobre o papel dos serviços públicos de saúde nesse mercado e, em especial, nos últimos anos, em que se observou o aumento da cobertura assistencial.

No terceiro capítulo, debate-se a base biotecnológica no Brasil, seus desafios e nichos estratégicos. Como contribuição para a reflexão sobre o CEIS, aponta-se que o Brasil é um dos poucos países com norma específica para produtos biológicos, elaborada pela Agência Nacional de Vigilância Sanitária (Anvisa). Observa-se que a crescente demanda por esses produtos é suprida por importações, o que causa um desequilíbrio na balança comercial. As importações de produtos biológicos cresceram aproximadamente o dobro do incremento para os demais produtos farmacêuticos.

Omissão observada nos segundo e terceiro capítulos é a ausência de análises sobre a indústria de hemoderivados. A inexistência de base produtiva nacional de plasma e derivados direcionou importantes investimentos governamentais, notadamente na Hemobrás (Empresa Brasileira de Hemoderivados e Biotecnologia). Muito embora seu funcionamento pleno estivesse previsto para $2014^{4}$, não se observa até o presente o seu impacto na obtenção da autossuficiência nacional. Essa análise crítica sobre esse segmento é uma lacuna importante no livro.

O quarto capítulo discute a base mecânica, eletrônica e de materiais. É realçada a melhora na qualidade das tecnologias fabricadas no país, em que a indústria de equipamentos médicos aparece como uma das mais inovadoras. Contudo, há uma perda de competitividade desse setor, em especial nos produtos de maior intensidade tecnológica. Observa-se o crescimento do déficit comercial no período, excetuando-se o setor odontológico, com balança superavitária, tendência constatada em estudo anterior 5 .

O capítulo aborda um tema central na reflexão sobre o CEIS, que é o do nicho de mercado em que o país se especializou. Os autores 
destacam a perda de competitividade observada nos produtos de baixa densidade tecnológica para nações como a China e Cingapura.

O quinto capítulo, Complexo Econômico-Industrial da Saúde, Segurança e Autonomia Estratégica: A Inserção do Brasil no Mundo, agrega a economia política internacional ao debate do CEIS. A autonomia estratégica refere-se ao grau de liberdade política de um Estado em adotar regras favoráveis ao seu desenvolvimento socioeconômico e à sua segurança diante dos interesses externos, nas políticas interna e externa.

Os autores definem a segurança em saúde como a capacidade de produção interna de bens e serviços de saúde que atendam às necessidades de sua população, seja em tempo de paz como em épocas de contenciosos e conflitos político-econômicos. Os autores propõem que a América do Sul, a África e os países do BRICS (Brasil, Rússia, Índia, China e África do Sul) sejam os principais parceiros potenciais do país no mercado globalizado.

Importância adicional deve ser remetida ao livro, pois a partir de sua publicação em 2016, ocorreram sensíveis mudanças na destinação dos recursos estatais, com limitação nos gastos públicos em políticas sociais e a redução da dimensão pública do papel do Estado, em especial após o impeachment de Dilma Roussef. Isso não se limitou ao campo da saúde, atingindo também a agenda sobre o desenvolvimentismo no país. Por fim, a abrangência na abordagem dos diferentes temas afetos ao conceito de CEIS recomenda a leitura. Trata-se de potente incremento à literatura existente na área, que é vital para a sustentabilidade do SUS e o desenvolvimento soberano do país.
Marco Antonio Manfredini 1

1 Universidade de São Paulo, São Paulo, Brasil.

manfra@uol.com.br

1. Gadelha CAG, Costa LS, Borges TR, Maldonado JMSV. O complexo econômico-industrial da saúde: elementos para uma articulação virtuosa entre saúde e desenvolvimento. Saúde Debate 2012; 36:21-30.

2. Cordeiro H. A indústria de saúde no Brasil. Rio de Janeiro: Edições Graal; 1980.

3. Grupo de Pesquisas de Inovação em Saúde, Escola Nacional de Saúde Pública Sergio Arouca, Vice-Presidência de Produção e Inovação em Saúde, Fundação Oswaldo Cruz. Informe CEIS 2010; 1(1). http://www.fiocruz.br/vppis/ imagens/ceis/Boletim\%20Complexo\%20Sau de\%20Vol\%201\%202010.pdf.

4. Gadelha CAG, Costa LS, Maldonado J. O complexo econômico-industrial da saúde e a dimensão social e econômica do desenvolvimento. Rev Saúde Pública 2012; 46 Suppl 1:21-8.

5. Manfredini MA, Botazzo C. Tendências da indústria de equipamentos odontológicos no Brasil entre 1990 e 2002: notas prévias. Ciênc Saúde Coletiva 2006; 11:169-77. 